\title{
Características do pasto e eficiência agronômica de nitrogênio em capim-tanzânia sob pastejo contínuo, adubado com doses de nitrogênio
}

\author{
Sward characteristics and agronomic efficiency of nitrogen on Tanzania grass under continuous \\ grazing fertilized with nitrogen levels
}

\author{
Marcos Weber do Canto $^{\mathrm{I}^{*}}$ André Ricardo Hoeschl ${ }^{\mathrm{II}}$ Amadeo Bona Filho ${ }^{\mathrm{II}}$ Aníbal de Moraes \\ Eliane Gasparino ${ }^{\mathrm{I}}$
}

\section{RESUMO}

\begin{abstract}
$O$ experimento foi conduzido visando a avaliar os efeitos das doses de nitrogênio (N) 100,200, 300 e 400kg ha-1 sobre as características do pasto e sobre a eficiência agronômica de $N$, em pastagens de capim-tanzânia (Panicum maximum Jacq. cv. 'Tanzânia-1') utilizadas com o método de pastejo contínuo. $O$ delineamento experimental foi o inteiramente ao acaso, com duas repetições. Foram utilizados três tourinhos testadores nas pastagens com a dose de $\mathrm{N}$ de $100 \mathrm{~kg} \mathrm{ha}^{-1}$ e quatro tourinhos testadores nas pastagens das demais doses de $N$, da raça Nelore (Bos indicus) e com peso médio inicial de $300 \mathrm{~kg}$, mantidos de 10/11/2001 a 15/4/2002. A altura do pasto foi mantida em $60 \mathrm{~cm}$ por ajustes da taxa de lotação. As massas de forragem, de folha verde, de forragem verde e de colmo elevaram-se linearmente com o aumento da adubação de $N$. Regressão linear negativa foi verificada entre as doses de $N$ e a razão folha:colmo. A participação de colmo se elevou e a de material morto se reduziu na estrutura do pasto com o aumento da adubação de N. Não houve efeito das doses de $N$ na proporção de folha verde na estrutura do pasto. Aplicações de $\mathrm{N}$ em pastagens de capimtanzânia utilizadas com o método de pastejo contínuo alteram características do pasto. A eficiência agronômica de $N$, definida em termos da razão acúmulo de matéria seca $(M S) \mathrm{kg}^{-1}$ de $N$ aplicado, reduziu-se com o aumento da dose de $N$.
\end{abstract}

Palavras-chave: estrutura do pasto, gramínea tropical, massa de forragem, massa de folha verde, Panicum maximum Jacq.

\section{ABSTRACT}

The experiment evaluated the effects of nitrogen $(N)$ levels $\left(100,200,300,400 \mathrm{~kg} \mathrm{ha}^{-1}\right)$ on sward characteristics, and agronomic efficiency of $N$ on Tanzania grass pastures (Panicum maximum Jacq. cv. 'Tanzânia-1') with continuous grazing method. The design experimental used was completely randomized with two replications. Three tester Nellore (Bos indicus) young bulls per pasture with $N$ level of $100 \mathrm{~kg} \mathrm{ha}^{-1}$, and four tester Nellore young bulls per pasture of the other $N$ levels, with $300 \mathrm{~kg}$ initial weight grazed continuously from 10 November 2001 to 15 April 2002. Sward height levels at experimental pastures were maintaining at $60 \mathrm{~cm}$ with adjusting of stocking rate. The herbage mass, green leaf mass, green herbage mass, and culm mass, increased linearly as the $N$ fertilization increased. Negatively linear relationship was found between the $N$ fertilization and leaf/ culm ratio. The culm proportion increased and dead material decreased on sward structure with increased $N$ levels applied at pasture. There were no effects of $N$ levels on green leaf proportion at sward structure. $N$ applications in Tanzania grass pastures change sward characteristics. The agronomic efficiency of $N$ defined in terms of dry matter (DM) accumulation/ $\mathrm{kg}$ of $N$ applied decreased with the increase of $N$ levels.

Key words: green leaf mass, herbage mass, Panicum maximum Jacq., sward structure, tropical grass.

\section{INTRODUÇÃO}

No estado do Paraná, a produtividade da bovinocultura de corte é baixa e as causas estão relacionadas, sobretudo, aos solos das pastagens que se encontram com baixa fertilidade e ao manejo do pastejo, executado com pouca consideração às condições dos pastos. Esse contexto pode ser alterado com a utilização de gramíneas tropicais com alta resposta produtiva de forragem, com alto valor alimentício e que proporcionem, para bovinos sob pastejo, altas taxas de consumo de forragem e de desempenho por animal. Essas características agronômicas são encontradas com o capim-tanzânia

'Departamento de Zootecnia, Universidade Estadual de Maringá (UEM), 87020-900, Maringá, PR, Brasil. E-mail: mwcanto@uem.br.

*Autor para correspondência.

"Universidade Federal do Paraná (UFPR), Curitiba, PR, Brasil. 
(CANTO, 2003; EUCLIDES et al., 2007b; DIFANTE et al., 2009).

As características do pasto são descritas pelas massas de forragem, lâmina de folha verde, colmo e de material morto, proporção de solo descoberto, altura do pasto, razão folha:colmo e pela composição botânica e morfológica na estrutura do pasto, expressa em base percentual ou concentração na MS ( $\mathrm{g} \mathrm{kg}^{-1}$ de MS), de lâmina de folha, colmo e material morto. Em gramíneas tropicais, BURNS \& SOLLENBERGER (2002) relatam que o consumo de forragem e o ganho de peso de animais em pastejo podem ser influenciados por características do pasto. BURNS et al. (1989) destacam que, sob pastejo, as massas de forragem e folha verde podem alterar o desempenho individual dos animais e a taxa de crescimento do pasto. Em pastos artificiais de Panicum maximum, o comportamento seletivo de pastejo de bovinos variou de acordo com a resistência à preensão dos colmos (BENVENUTTI et al., 2008). Estudos mostram que, em pastagens de capimtanzânia sob pastejo contínuo, durante a estação do inverno, a altura do pasto pode alterar características do pasto (CANTO et al., 2001) e, em consequência, o desempenho de novilhos de corte (CANTO et al., 2002). Os trabalhos com essa gramínea com o método de pastejo rotativo indicam que a altura do pasto afetou características do pasto, o valor nutritivo (DIFANTE et al., 2009), a conversão alimentar, o desempenho por animal e o ganho/ha (DIFANTE et al., 2010).

O desenvolvimento de práticas culturais de adubações de $\mathrm{N}$ exige o conhecimento de como estas afetam características do pasto. A massa de forragem em pastagens de capim-milênio (Panicum maximum), sob pastejo rotativo, aumentou com maiores doses de N (SARMENTO et al., 2005). Em pastagens de capim-tanzânia, utilizadas por tourinhos Nelores e sob pastejo contínuo, o aumento na dose de $\mathrm{N}$ até $600 \mathrm{~kg} \mathrm{ha}^{-1}$ elevou as massas de forragem, folha verde e de colmo verde (CANTO, 2003). EUCLIDES et al. (2007a) reportam que, nessa gramínea, a aplicação adicional de $\mathrm{N}$, em março, elevou as massas de material verde e folha verde. HERINGER \& MOOJEN (2002) avaliando capimmilheto [Pennisetum americanum (L.) Leeke], verificaram que o aumento na adubação de $\mathrm{N}$ elevou a proporção de folhas.

A utilização extensiva de adubações nitrogenadas justifica pesquisas para avaliar a eficiência agronômica de $\mathrm{N}$ em pastagens. A adubação de $\mathrm{N}$ representou considerável fração dos custos da intensificação da produção de forragem em pastagens (LUPATINI, 1996). CORSI \& NUSSIO (1992) relatam que, em Panicum maximum, há possibilidade de resposta à adubação de $\mathrm{N}$ até a faixa de 400 a $800 \mathrm{~kg} \mathrm{ha}^{-1}$. No entanto, os autores citam que normalmente a eficiência de conversão de $\mathrm{N}$ da adubação em forragem é de 40 a $70 \mathrm{~kg}$ de $\mathrm{MS} \mathrm{kg}^{-1}$ de $\mathrm{N}$ aplicado. MELLO et al. (2008), ao testarem em capim-mombaça (Panicum maximum Jacq. cv. 'Mombaça') doses de $\mathrm{N}$ até $500 \mathrm{~kg} \mathrm{ha}^{-1}$, na forma de sulfato de amônio, porém sob condições de corte, observaram melhor eficiência de conversão do $\mathrm{N}$ da adubação em forragem com $307 \mathrm{~kg} \mathrm{ha}^{-1}$.

Estudos em pastagens de capim-tanzânia utilizadas por bovinos de corte sob pastejo contínuo, em que as características do pasto e a eficiência agronômica de $\mathrm{N}$ foram avaliadas, são pouco encontrados. A hipótese deste trabalho é a de que, em pastagens de capim-tanzânia, o aumento na dose de $\mathrm{N}$ poderia afetar essas variáveis. Objetivou-se neste experimento avaliar, em pastagens de capim-tanzânia, utilizadas por tourinhos Nelores sob pastejo contínuo, os efeitos de doses de $\mathrm{N}$ sobre as características e a composição morfológica do pasto e sobre a eficiência agronômica de $\mathrm{N}$.

\section{MATERIAL E MÉTODOS}

Oexperimento foi conduzido de 10/11/2001 a 15/4/2002 na Fazenda Nossa Senhora Aparecida, Noroeste do Paraná (23018'24,79”, 51 51 '02,61”W e altitude de $405,7 \mathrm{~m})$. O clima na região é o Cfa, de acordo com a classificação de Köppen, e as médias de chuvas em dezembro, janeiro, fevereiro, março e abril são, respectivamente, de 202, 192, 154, 147 e $130 \mathrm{~mm}$. A precipitação pluviométrica do período experimental foi de $788 \mathrm{~mm}$ e as demais variáveis de clima favoreceram o crescimento do capim-tanzânia. O solo da área é classificado como Latossolo Vermelho distroférrico argiloso (EMBRAPA, 2006).

Os oito piquetes foram estabelecidos com a cultivar 'Tanzânia-1' em setembro de 1998. A área de cada piquete foi aproximadamente 1,0ha e a área total abrangeu 8,9ha. Adubações de $180 \mathrm{~kg} \mathrm{ha}^{-1}$ de $\mathrm{P}_{2} \mathrm{O}_{5}$ (superfosfato simples) e de N (ureia) de $250 \mathrm{~kg}$ $\mathrm{ha}^{-1}$ foram realizadas na área experimental em $1998 \mathrm{e}$ 1999. Em setembro de 2000, foram aplicados ao solo $120 \mathrm{~kg} \mathrm{ha}^{-1}$ de $\mathrm{P}_{2} \mathrm{O}_{5}$ (superfosfato simples). A análise do solo teve como características químicas: $\mathrm{pH}$ $\mathrm{CaCl}_{2}=5,4 ; \mathrm{Al}^{+3}=0,0 \mathrm{cmol}_{\mathrm{c}} \mathrm{dm}^{-3} ; \mathrm{H}^{++} \mathrm{Al}^{+3}=3,66 \mathrm{cmol}_{\mathrm{c}}$ $\mathrm{dm}^{-3}, \quad \mathrm{Ca}^{++}=7,7 \mathrm{cmol}_{\mathrm{c}} \quad \mathrm{dm}^{-3} ; \quad \mathrm{K}^{+}=0,63 \mathrm{cmol}_{\mathrm{c}} \mathrm{dm}^{-3} ;$ $\mathrm{P}=8,4 \mathrm{mg} \mathrm{dm}^{-3}$ e C=14,5 $\mathrm{g} \mathrm{dm}^{-3}$. A adubação fosfatada de $90 \mathrm{~kg} \mathrm{ha}^{-1}$ de $\mathrm{P}_{2} \mathrm{O}_{5}$ (superfosfato simples) em cobertura foi em novembro de 2001. A calagem e a 
adubação de potássio não foram realizadas em razão dos teores no solo.

$\mathrm{O}$ delineamento experimental foi $\mathrm{o}$ inteiramente ao acaso, com duas repetições. Os tratamentos foram as doses de N 100, 200, $300 \mathrm{e}$ $400 \mathrm{~kg} \mathrm{ha}^{-1}$. A adubação de $\mathrm{N}$ foi a lanço com nitrato de amônio $\left(\mathrm{NH}_{4} \mathrm{NO}_{3}\right)$ em três aplicações $(21 / 11 / 2001$, $15 / 01 / 2001,05 / 02 / 2002)$, igualmente fracionadas as doses de $\mathrm{N}$ testadas, de 200, 300 e $400 \mathrm{~kg} \mathrm{ha}^{-1}$. Nos piquetes da dose de $\mathrm{N}$ de $100 \mathrm{~kg} \mathrm{ha}^{-1}$, as adubações de $\mathrm{N}$ foram realizadas com 33,4 e $66,6 \mathrm{~kg} \mathrm{ha}^{-1}$, respectivamente, em 21/11/2001 e 15/01/2002.

Os animais testadores e reguladores utilizados foram machos não castrados da raça Nelore, com peso médio inicial próximo de $300 \mathrm{~kg}$. Nos piquetes com a dose de $\mathrm{N}$ de $100 \mathrm{~kg} \mathrm{ha}^{-1}$, foram mantidos três tourinhos Nelores testadores e, nos demais, quatro tourinhos Nelores testadores. Os tourinhos reguladores, temporariamente fora dos piquetes experimentais, foram mantidos em uma pastagem adjacente de capim-tanzânia. O método de pastejo contínuo foi usado com taxas de lotação variável (MOTT \& LUCAS, 1952) para o controle da altura do pasto, preestabelecida em $60 \mathrm{~cm}$. CANTO et al. (2008) preconizou altura do pasto entre 40 a $60 \mathrm{~cm}$ em pastagens de capim-tanzânia sob pastejo contínuo. Os detalhes da condução do experimento a campo e os resultados de ganho de peso diário/animal, taxa de lotação e ganho/ha e relações entre características do pasto com o desempenho/animal, foram descritos em CANTO et al. (2009). Resumidamente, os ajustes da taxa de lotação foram em intervalos de 14 dias. A altura do pasto foi avaliada por meio de régua, efetuandose 50 leituras aleatórias semanais em cada piquete. As observações foram realizadas na folha superior do perfilho, que se encostou à régua, considerandose o nível do solo. As médias de altura do pasto nas pastagens das doses de $\mathrm{N}$ de 100, 200, 300 e 400kg ha ${ }^{-1}$ foram, respectivamente, 55, 61, 62 e 62cm, próximas da preestabelecida. A média de taxa de lotação, nas doses de N 100, 200, 300 e 400 $\mathrm{kg} \mathrm{ha}^{-1}$ foi, respectivamente, $1.332,2.129,2.790$ e $3.047 \mathrm{~kg} \mathrm{ha}^{-1}$.

O método da dupla amostragem (WILM et al., 1944) foi usado para avaliação da massa de forragem. A forragem amostrada foi cortada rente ao solo com tesoura de poda, usando-se moldura de ferro com área de um $(1,0 \mathrm{x} 1,0) \mathrm{m}^{2}$. As amostras foram mantidas em freezer e procedeu-se à separação dos componentes morfológicos lâmina de folha, colmo e material morto e, a seguir, foram colocados em estufa a ar forçado $\left(60^{\circ} \mathrm{C}\right)$ por 56 horas para determinação da MS. A equação de GARDNER (1986) permitiu o cálculo da massa de forragem. As proporções de solo descoberto e solo coberto com liteira foram avaliados visualmente, conforme THOMAS (1980). A eficiência agronômica de $\mathrm{N}$ foi definida em termos da razão acúmulo de $\mathrm{MS} \mathrm{kg}^{-1}$ de $\mathrm{N}$ aplicado (KATA \& BROADBENT, 1988), sendo usados os valores de acúmulo de MS apresentados por HOESCHL et al. (2007).

As relações das variáveis dependentes com as doses de $\mathrm{N}$ foram analisadas por equações de regressão (SAS INSTITUTE, 2002). O modelo linear e o modelo quadrático foram testados e selecionouse o modelo de acordo com a significância dos coeficientes de regressão, adotando-se o nível de 5\% de probabilidade, e o coeficiente de determinação.

\section{RESULTADOS E DISCUSSÃO}

A relação das doses de $\mathrm{N}$ com as massas de forragem, forragem verde, folha verde e de colmo se ajustou melhor ao modelo linear positivo (Figura 1). $\mathrm{O}$ aumento na dose de $\mathrm{N}$ não influenciou $(\mathrm{P}<0,05)$ na massa de material morto. As médias de massa de material morto nas doses de N 100, 200, 300 e 400kg $\mathrm{ha}^{-1}$ foram, respectivamente, 2.621, 3.377, $2.613 \mathrm{e}$ $3.072 \mathrm{~kg}$ de MS ha-1.

Experimentos em pastagens de Panicum maximum conduzidos sob pastejo rotativo (EUCLIDES et al., 2007a; SARMENTO et al., 2005) revelam também que a maior taxa de aplicação de $\mathrm{N}$ resultou em aumento das massas de forragem e lâminas foliares. No presente trabalho, nas pastagens com as mais altas doses de $\mathrm{N}$, a maior disponibilidade de $\mathrm{N}$ no solo pode ter favorecido o aumento da densidade populacional de perfilhos. Adicionalmente, com doses mais altas de N, observam-se, na estrutura de perfilhos, aumento nas taxas de aparecimento e de alongamento de folha e maior longevidade de folha. Esses processos morfogênicos têm sido reportados em experimentos com gramíneas tropicais submetidas a doses de N (CANTO, 2003; FAGUNDES et al., 2006; PAIVA et al., 2012).

Os resultados de massa de forragem e de massa de folha verde foram superiores aos verificados por CANTO et al. (2008), em capim-tanzânia com altura do pasto mantida em $60 \mathrm{~cm}$. Podem-se mencionar, em bases comparativas, que as massas de forragem e folha verde foram superiores às relatadas por SETELICH (1999), em experimento com capimelefante anão (Pennisetum purpureum Schum cv. 'Mott') sob pastejo contínuo e mantido com altura do pasto próxima de $60 \mathrm{~cm}$, em que foram avaliadas doses de $\mathrm{N}$ até $750 \mathrm{~kg} \mathrm{ha}^{-1}$. Nesse estudo de pastejo, as médias de massa de lâmina foliar nas doses de $\mathrm{N}$ zero, 250, 500 e $750 \mathrm{~kg} \mathrm{ha}^{-1}$, nos períodos de outubro/1996 

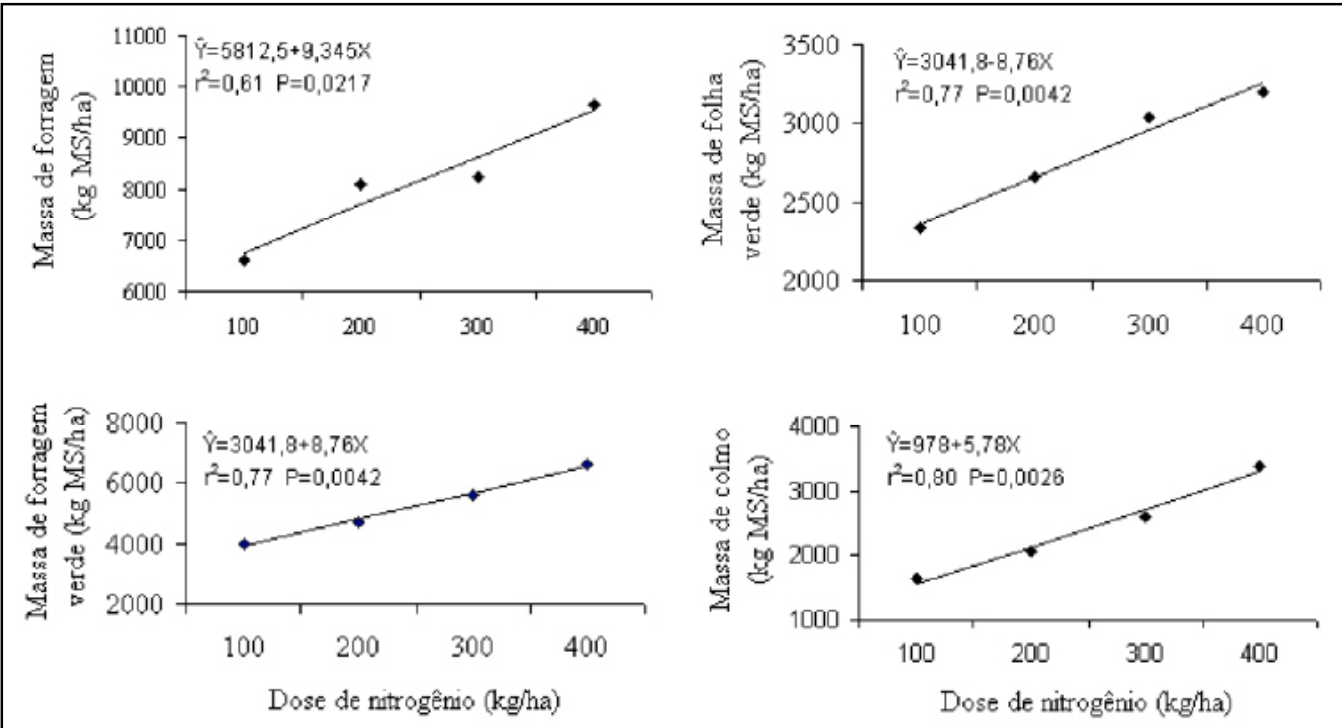

Figura 1 - Massa de forragem, massa de folha verde, massa de forragem verde e massa de colmo.

a abril/1997 e outubro/1997 a abril/1998 foram, respectivamente, $2.101,2.174,2.380$ e $2.381 \mathrm{~kg}$ de MS ha $^{-1}$. ALMEIDA et al. (2000), em capim-elefante anão, cultivar 'Mott', sob pastejo contínuo utilizado por bovinos de corte, indicam que a oferta de forragem por volta de 10 a $11 \mathrm{~kg}$ de MS de lâminas foliares $/ 100 \mathrm{~kg}$ de peso vivo/dia determinou altura do pasto próxima de $60 \mathrm{~cm}$ e massa de folha verde de $2.332 \mathrm{~kg}$ de MS $\mathrm{ha}^{-1}$. Segundo os autores, massa de folha verde por volta de $2.200 \mathrm{~kg}$ de $\mathrm{MS} \mathrm{ha}{ }^{-1}$ determina o potencial de desempenho por animal e assegura condições que beneficiam a persistência do pasto.

No caso deste trabalho, o aumento da massa de colmo pode estar relacionado à elevação da densidade de perfilhos nos pastos com as mais altas doses de N. Efeito do aumento da dose de $\mathrm{N}$ sobre o aumento de colmo na massa de forragem foi por igual reportado por CANTO (2003) em capimtanzânia e por FAGUNDES et al. (2006), em capimbraquiária [Urochloa decumbens (Stapf) Webster cv. 'Basilisk']. A falta de significância entre a massa de material morto e as doses de $\mathrm{N}$ foi relatada também por CANTO (2003), que observaram que as doses de $\mathrm{N}$ zero, 200, 400 e $600 \mathrm{~kg} \mathrm{ha}^{-1}$ determinaram, na média, variação na massa de material morto de 1.147 a $1.275 \mathrm{~kg}$ de $\mathrm{MS} \mathrm{ha}{ }^{-1}$. É sabido que a produtividade animal em pastagens é relacionada às características do pasto (HODGSON, 1990; HACK et al., 2007; DIFANTE et al., 2010). As condições em que são mantidos os pastos apresentam implicações sobre a sua produtividade nos anos subsequentes e sobre a sua persistência.

Houve efeito linear positivo da dose de $\mathrm{N}$ sobre a proporção de colmo e a proporção de material morto, razão folha:colmo e a eficiência agronômica de $\mathrm{N}$, expressa pela razão acúmulo de $\mathrm{MS} / \mathrm{kg}$ de $\mathrm{N}$ aplicado, decresceram linearmente com o aumento da dose de N (Figura 2). A razão folha:colmo e a eficiência agronômica de $\mathrm{N}$ nas doses de N 100, 200, 300 e $400 \mathrm{~kg} \mathrm{ha}^{-1}$ variaram, respectivamente, de 1,3 a 0,8 e de 191,2 a $83,9 \mathrm{~kg}$ de $\mathrm{MS} \mathrm{kg}^{-1}$ de $\mathrm{N}$ aplicado na pastagem. Não houve diferença $(\mathrm{P}>0,05)$ na proporção de folha verde na estrutura do pasto com o aumento da dose de N. Nas doses de N 100, 200, 300 e $400 \mathrm{~kg} \mathrm{ha}^{-1}$, as médias constatadas de proporção de folha verde foram, respectivamente, de 35,1; 32,2; 34,6 e 32,2 $\mathrm{g} \mathrm{kg}^{-1}$ de MS.

A alta participação de material morto nos pastos com as mais baixas adubações de $\mathrm{N}$ pode ser explicada pela alta fração de colmos amarelecidos. MATHEWS et al. (2004) citam que gramíneas tropicais submetidas a doses de $\mathrm{N}$ relativamente baixas à absorção de $\mathrm{N}$ é menor e, em decorrência, a assimilação do $\mathrm{N}$ (incorporação do $\mathrm{N}$ em aminoácidos, enzimas ou compostos com N) na parte aérea da planta é reduzida, o que resulta em baixo teor de $\mathrm{N}$ nas plantas. $\mathrm{Na}$ literatura, muitos trabalhos indicam que gramíneas tropicais com baixo teor de $\mathrm{N}$ na parte aérea, devido ao pouco $\mathrm{N}$ disponível no solo ou da adubação, apresentam-se amarelecidas, 

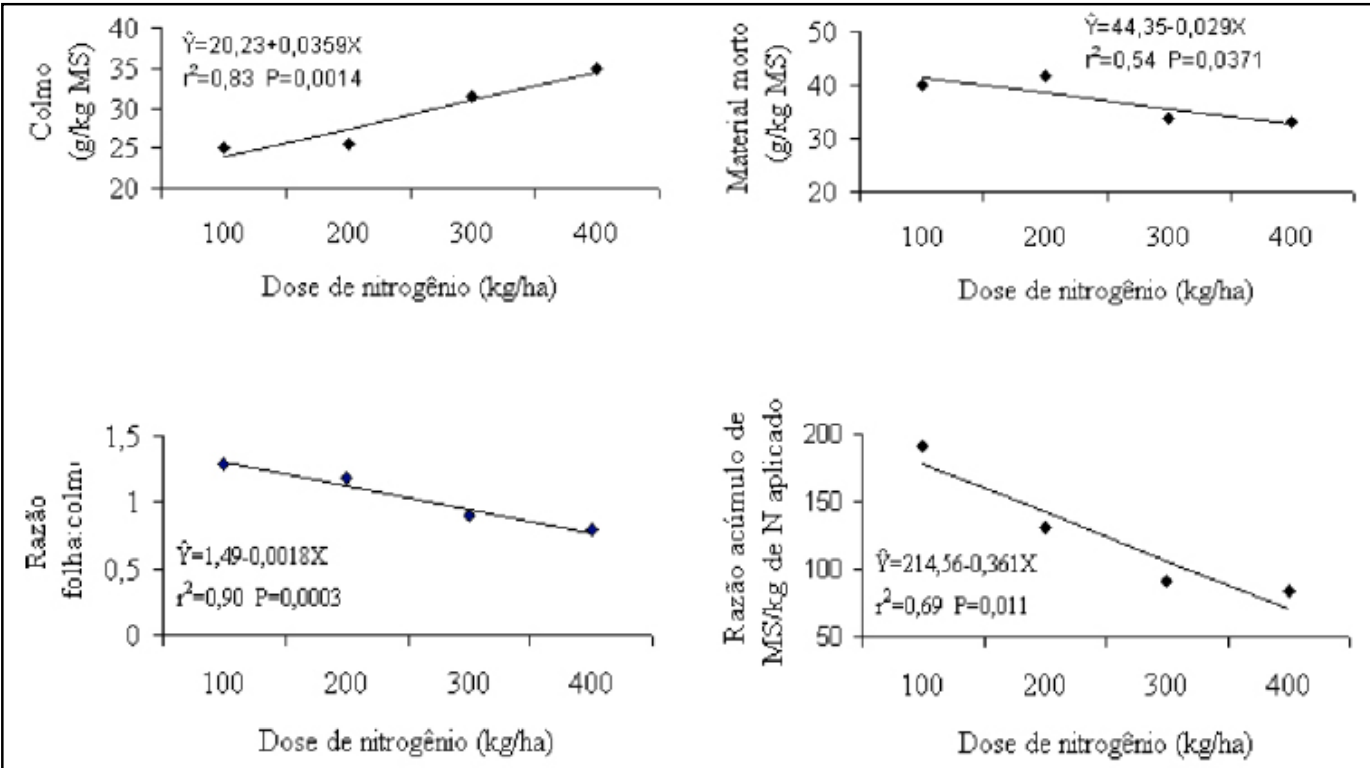

Figura 2 - Participação de colmo, de material morto, razão folha:colmo e eficiência agronômica de nitrogênio, expressa pela razão acúmulo de matéria seca/kg de nitrogênio aplicado.

pouco folhosas e com proporção alta de colmo. No estudo de pastejo realizado por CANTO (2003), os pastos de capim-tanzânia com as menores doses de $\mathrm{N}$ também apresentaram aumento e decréscimo, respectivamente, nas porcentagens de colmo e de material morto na massa de forragem.

Com relação aos pastos com as doses de $\mathrm{N}$ mais altas, a resposta na porcentagem de colmo e de material morto pode estar associada à luz interceptada pela superfície foliar. Segundo NELSON \& MOSER (1994), em pastos com alto índice de área foliar, a penetração de luz é dificultada nas porções do dossel do pasto próximas do solo. Esses autores citam que, nos estratos inferiores do pasto, verificou-se alta taxa de mortalidade dos perfilhos mais jovens, alta participação de folhas senescentes e a intensificação no alongamento dos entrenós dos colmos. Nessas situações, ocorre a predominância dos colmos e de folhas senescentes nas camadas mais baixas do dossel do pasto (HODGSON, 1990; ALMEIDA et al., 2000). Além disso, na camada inferior do pasto, o componente colmo apresenta, na composição do tecido, concentração de MS mais elevada, se comparado às camadas intermediárias e superiores da estrutura do pasto (HODGSON, 1990). A falta de diferença na proporção de folha verde em capimtanzânia adubado com doses de $\mathrm{N}$ foi reportada por CANTO (2003).

$\mathrm{O}$ aumento da dose de $\mathrm{N}$ determinou redução da razão folha:colmo provavelmente em consequência do aumento da densidade de perfilhos e da participação dos colmos na massa de forragem (Figura 2). Os resultados de razão folha:colmo foram próximos aos de LUPATINI (1996) em capim-milheto, avaliando as doses de $\mathrm{N}$ zero, 150, 300, 450 e $600 \mathrm{~kg}$ $\mathrm{ha}^{-1}$, em que a razão folha:colmo variou de 0,99 a 1,20 e, contrariamente ao observado neste experimento, não houve efeito da dose de N. Entretanto, os estudos de pastejo com o capim-tanzânia sob pastejo contínuo (CANTO, 2003) e sob pastejo rotativo (EUCLIDES et al., 2007a) demonstram que houve redução das lâminas foliares em relação aos colmos, à medida que aumentou a taxa de aplicação de N.

De acordo com a equação de regressão, cada quilograma de $\mathrm{N}$ aplicado reduziu a conversão de $\mathrm{N}$ em forragem em 20,2 (142,36); 40,5 (106,26) e $60,7 \%\left(70,16 \mathrm{~kg}\right.$ de $\mathrm{MS} \mathrm{kg}^{-1}$ de $\left.\mathrm{N}\right)$, nas doses de $\mathrm{N}$ 200, 300 e 400kg ha-1, respectivamente, em relação à dose de $\mathrm{N}$ de $100 \mathrm{~kg} \mathrm{ha}^{-1}\left(178,46 \mathrm{~kg}\right.$ de $\mathrm{MS} \mathrm{kg}^{-1}$ de $\mathrm{N})$. Pesquisas mostram que a eficiência agronômica de $\mathrm{N}$ na produtividade de forragem normalmente é reduzida com o aumento da adubação de $\mathrm{N}$ na pastagem (FAGUNDES et al., 2006; SILVEIRA et al., 2007; MELLO et al., 2008).

Para as culturas de cereais mais importantes, HIREL et al. (2007) observam que a recuperação do $\mathrm{N}$ na cultura resulta do balanço entre a absorção de $\mathrm{N}$ na cultura e a imobilização de $\mathrm{N}$ no solo por processos microbianos de diversas composições. De acordo com os autores, a complexidade e a interação desses 
processos afetam a assimilação do $\mathrm{N}$, o crescimento e a produção das plantas. Adicionalmente, a fonte e a época de aplicação de $\mathrm{N}$, o método de manejo do pastejo, a textura do solo, as condições de fertilidade no solo e os demais fatores ambientais, podem atuar e influenciar na eficiência de absorção de $\mathrm{N}$ e alterar a produtividade de forragem. Essas são as razões prováveis pela qual os efeitos de adubações de $\mathrm{N}$ em pastos tropicais na eficiência agronômica de $\mathrm{N}$ são pouco entendidos. Por outro lado, com doses mais altas de $\mathrm{N}$, o $\mathrm{N}$ residual no solo é maior, porém a eficiência de absorção de $\mathrm{N}$ no pasto pode reduzir e podem causar no solo redução no $\mathrm{pH}$, acentuar a acidez e reduzir a disponibilidade de nutrientes, sobretudo de macronutrientes (MATHEWS et al., 2004; SILVEIRA et al., 2007).

Com o aumento da adubação de N, a fração de solo desnudo se reduziu e a de solo coberto com os restos de plantas mortas aumentou. Conforme o modelo de regressão, a proporção de solo descoberto ( $Y=3,509$ $\left.0,0027 \mathrm{X} ; \mathrm{r}^{2}=0,56 ; \mathrm{P}=0,03\right)$ e a de solo coberto com liteira $\left(\mathrm{Y}=5,936+0,0111 \mathrm{X} ; \mathrm{r}^{2}=0,86 ; \mathrm{P}=0,01\right)$ nas doses de $\mathrm{N}$ $100,200,300$ e $400 \mathrm{~kg} \mathrm{ha}^{-1}$ variou, respectivamente, de 2,4 a $3,2 \%$ e de 7,0 a $10,4 \%$.

Isso pode ser explicado em razão de que o aumento da dose de $\mathrm{N}$ elevou as massas de forragem e de folha verde (Figura 1) e isso reduziu a proporção de solo descoberto. Por outro lado, é provável que nessas maiores massas a senescência de tecidos foliares tenha sido maior, o que determinou maiores áreas cobertas com liteira.

\section{CONCLUSÃO}

Os resultados obtidos suportam a hipótese de que o aumento na dose de nitrogênio afeta características do pasto e a eficiência agronômica de nitrogênio em capim-tanzânia, utilizando bovinos de corte sob pastejo contínuo e altura do pasto próxima de $60 \mathrm{~cm}$. As massas de forragem, de folha verde e de colmo aumentam linearmente até a dose de nitrogênio de $400 \mathrm{~kg} \mathrm{ha}^{-1}$. Na composição morfológica do pasto, a adubação de nitrogênio aumenta o componente colmo, reduz o material morto e a proporção de folha verde não é alterada. A eficiência agronômica de conversão de nitrogênio em forragem é reduzida com o aumento da taxa de aplicação de nitrogênio.

\section{REFERÊNCIAS}

ALMEIDA, E.X. et al. Oferta de forragem de capim-Elefante Anão 'Mott' e o rendimento animal. Revista Brasileira de Zootecnia, v.29, p.1288-1295, 2000. Disponível em: <http:// www.scielo.br/scielo.php?script=sci_arttext $\&$ pid $=$ S 1516 -
$35982000000500005 \& \operatorname{lng}=$ pt\&nrm=iso $>$. Acesso em: 16 nov. 2010. doi: 10.590/S1516-3598000000500005.

BENVENUTTI, M.A. et al. The effects of stem density of tropical swards and age of grazing cattle on their foraging behavior. Grass and Forage Science, v.63, p.1-8, 2008. Disponível em: <http:// onlinelibrary.wiley.com/doi/10.1111/j.1365-2494.2007.00609.x/ full>. Acesso em: 14 jun. 2012. doi: 10.1111/j.13652494.2007.00609.x.

BURNS, J.C. et al. The relationship of herbage mass and characteristics to animal responses in grazing experiments. In: MARTEN, G.C. Grazing research: design, methodology, and analysis. Madison: Crop Science Society, American Society of Agronomy, 1989. Cap.2, p.7-19.

BURNS, J.C.; SOLLENBERGER, L.E. Grazing behavior of ruminants and daily performance from warm season grasses. Crop Science, v.42, p.873-881, 2002. Disponível em: <http://www. crops.org/publications/cs/abstracts/42/3/873>. Acesso em: 10 jun. 2011. doi: $10.2135 /$ cropsci2002.8730.

CANTO, M.W. et al. Animal production in Tanzania grass swards fertilized with nitrogen. Revista Brasileira de Zootecnia, v.38, p.1176-1182, 2009. Disponível em: <http://www.scielo.br/scielo. php? script=sci_arttext\&pid=S1516-35982009000700003\&lng =pt\&nrm=iso $>$. Acesso em: 1 jan. 2011. doi: 10.590/S151635982009000700003.

CANTO, M.W. et al. Características do pasto e acúmulo de forragem em capim-tanzânia submetido a alturas de manejo do pasto. Pesquisa Agropecuária Brasileira, v.43, p.429-435, 2008. Disponível em: <http://www.scielo.br/scielo.php?script=sci arttext\&pid=S0100-204X2008000300019\&lng=pt\&nrm=iso $>$. Acesso em: 15 abr. 2011. doi: 10.590/S0100-204X2008000300019.

CANTO, M.W. Dinâmica de crescimento e produção animal em capim Tanzânia adubado com doses de nitrogênio. 2003. 194f. Tese (Doutorado em Agronomia) - Curso de Pós-graduação em Produção Vegetal, Universidade Federal do Paraná, PR.

CANTO, M.W. et al. Produção animal no inverno em capimTanzânia diferido no outono e manejado em diferentes alturas de pasto. Revista Brasileira de Zootecnia, v.31, p.1624-1633, 2002. Disponível em: <http://www.scielo.br/scielo.php?script=sci_ arttext \&pid=S1516-35982002000700004\&lng=pt\&nrm=iso $>$. Acesso em: 10 jan. 2011. doi: 10.590/S1516-35982002000700004.

CANTO, M.W. et al. Efeito da altura do capim-Tanzânia diferido nas características da pastagem no período do inverno. Revista Brasileira de Zootecnia, v.30, p.1186-1193, 2001. Disponível em: <http://www.scielo.br/scielo.php?script=sci_arttext\&pid=S151635982001000500008\&lng=pt\&nrm=iso $>$. Acesso em: 18 jan. 2011. doi: 10.590/S1516-35982001000500008.

CORSI, M.; NUSSIO, L.G. Manejo do capim-elefante: correção e adubação do solo. In: SIMPÓSIO SOBRE MANEJO DE PASTAGENS, 10., 1992, Piracicaba, SP. Anais... Piracicaba: FEALQ, 1992. p.87-116.

EMBRAPA. Sistema brasileiro de classificação de solos. 2.ed. Rio de Janeiro: Embrapa. Centro Nacional de Pesquisa de Solos, 2006. 306p.

DIFANTE, G.S. et al. Desempenho e conversão alimentar de novilhos de corte em capim-tanzânia submetido a duas intensidades de pastejo sob lotação rotativa. Revista Brasileira de Zootecnia, 
v.39, p.33-41, 2010. Disponível em: <http://www.scielo.br/scielo. php?script $=$ sci_arttext\&pid=S1516-35982010000100005\&lng $=$ pt\&nrm=iso $>$. Acesso em: 15 jan. 2011. doi: 10.590/S151635982010000100005 .

DIFANTE, G.S. et al. Sward structure and nutritive value of Tanzania guineagrass subjected to rotational stocking managements. Revista Brasileira de Zootecnia, v.38, p.9-19, 2009. Disponível em: $<\mathrm{http}: / /$ www.scielo.br/scielo.php?script=sci_ arttext\&pid=S1516-35982009000100002\&lng=pt\&nrm=iso $>$. Acesso em: 10 jan. 2011. doi: 10.590/S1516-35982009000100002.

EUCLIDES, V.P.B. et al. Características do pasto de capim-tanzânia adubado com nitrogênio no final do verão. Pesquisa Agropecuária Brasileira, v.42, p.1189-1198, 2007a. Disponível em: <http:// www.scielo.br/scielo.php?script=sci_arttext\&pid=S0100-204X20 07000800017\&lng=pt\&nrm=iso >. Acesso em: 23 abr. 2011. doi: 10.590/S0100-204X2007000800017.

EUCLIDES, V.P.B. et al. Eficiência biológica e econômica de pasto de capim-tanzânia adubado com nitrogênio no final do verão. Pesquisa Agropecuária Brasileira, v.42, p.13451355, 2007b. Disponível em: <http://www.scielo.br/scielo. php? script $=$ sci_arttext\&pid $=$ S0100-204X2007000900017\&ln $\mathrm{g}=$ pt\&nrm=iso . Acesso em: 23 abr. 2011. doi: 10.590/S0100204X2007000900017.

FAGUNDES, J.L. et al. Avaliação das características estruturais do capim-braquiária em pastagens adubadas com nitrogênio nas quatro estações do ano. Revista Brasileira de Zootecnia, v.36, p.30-37, 2006. Disponível em:<http://www.scielo.br/scielo. php?script=sci_arttext\&pid=S1516-35982006000100004\&lng $=$ pt\&nrm=iso>. Acesso em: 10 fev. 2011. doi: 10.590/S151635982006000100004 .

GARDNER, A.L. Técnicas de pesquisa em pastagens e aplicabilidade de resultados em sistemas de produção. Brasília: Embrapa, 1986. 197p.

HACK, E.C. et al. Características estruturais e produção de leite em pastos de capim-mombaça (Panicum maximum Jacq.) submetidos a diferentes alturas de pastejo. Ciência Rural, v.37, p.218-222, 2007. Disponível em:<http://www.scielo.br/scielo. php?script=sci_arttext\&pid=S0103-84782007000100035\&lng= pt\&nrm=iso>. Acesso em: 16 nov. 2010. doi: 10.1590/S010384782007000100035 .

HERINGER, I.; MOOJEN, E.L. Potencial produtivo, alterações da estrutura e qualidade da pastagem de Milheto submetida a diferentes níveis de nitrogênio. Revista Brasileira de Zootecnia, v.31, supl., p.875-882, 2002. Disponível em: <http://www.scielo.br/scielo. php?script=sci_arttext $\&$ pid=S1516-35982002000400010\&lng =pt\&nrm=iso>. Acesso em: 12 fev. 2011. doi: 10.590/S151635982002000400010 .

HIREL, B. et al. The challenge of improving nitrogen use efficiency in crop plants: towards a more central role for genetic variability and quantitative genetics within integrated approaches. Journal of Experimental Botany, v.58, p.2369-2387, 2007. Disponível em: <http://jxb.oxfordjournals.org/content/58/9/2369. full>. Acesso em: 16 jun. 2012. doi: 10.1093/jxb/erm097.

HODGSON, J. Grazing management: science into practice. Harlow: Longman Scientific \& Technical, 1990. 203p.

HOESCHL, A.R. et al. A produção de forragem e perfilhamento em pastos de capim Tanzânia adubados com doses de nitrogênio. Scientia Agraria., v.8, p.81-86, 2007.
KATA, S.K.; BROADBENT, F.E. Methodology for evaluating nitrogen utilization efficiency by Rice genotypes. Agronomy Journal, v.80, p.793-798, 1988.

LUPATINI, G.C. Produção animal em milheto (Pennisetum americanum (L.) Leeke) submetido a níveis de adubação nitrogenada. 1996. 129f. Dissertação (Mestrado em Zootecnia) - Curso de Pós-graduação em Zootecnia, Universidade Federal de Santa Maria, RS

MATHEWS, B.W. et al. Mineral nutrition of $\mathrm{C}_{4}$ forage grasses In: MOSER, L.E. et al. Warm-Season $\left(\mathbf{C}_{4}\right)$ Grasses. Madison: American society of Agronomy, Crop Science Society of America, Soil Science Society of America, 2004. Cap.7, p.217-265.

MELLO, S.Q.S. et al. Adubação nitrogenada em capim-mombaça: produção, eficiência de conversão e recuperação aparente do nitrogênio. Ciência Animal Brasileira, v.9, p.935-947, 2008.

MOTT, G.O.; LUCAS, H.L. The design, conduct and interpretation of grazing trials on cultivated and improved pastures. In: INTERNATIONAL GRASSLAND CONGRESS, 6., 1952, Pennsylvania. Proceedings... Pennsylvania: State College, 1952. p.1380-1385.

NELSON, C.J.; MOSER, L.E. Plant factors affecting forage quality. In: FAHEY Jr., G.C. Forage quality, Evaluation, and Utilization. Madison: American society of Agronomy, Crop Science Society of America, Soil Science Society of America, 1994. Cap.3, p.115-154.

PAIVA, J.P. et al. Structural characteristics of tiller age categories of continuously stocked marandu palisade grass swards fertilized with nitrogen. Revista Brasileira de Zootecnia, v.41, p.24-29, 2012. Disponível em: <http://www.scielo.br/scielo. php?script=sci_arttext\&pid=S1516-35982012000100004\&lng $=$ pt\&nrm=iso>. Acesso em: 12 jun. 2012. doi: 10.590/S151635982012000100004

SARMENTO, P. et al. Respostas agronômicas e morfológicas de Panicum maximum JACQ. CV. 'IPR-86 Milênio, sob pastejo, a adubação nitrogenada. Boletim da Indústria Animal, v.62, p.333-346, 2005.

SAS INSTITUTE (Cary, United States). SAS user's guide: statistics. Cary, 2002. 419p.

SETELICH, H.A. Resposta a adubação nitrogenada de capim elefante anão (Pennisetum purpureum Schum. cv. 'Mott'). sob pastejo no alto Vale do Itajaí, Santa Catarina. 1999. 132f. Tese (Doutorado em Zootecnia) - Curso de Pós-graduação em Zootecnia, Universidade Federal do Rio Grande do Sul, RS

SILVEIRA, M.L. et al. Response of Coastal Bermudagrass yield and nutrient uptake efficiency to nitrogen sources. Agronomy Journal, v.99, p.707-714, 2007. Disponível em: <http://www. agronomy.org/publications/aj/articles/99/3/707?highlight=>. Acesso em: 12 jun. 2011. doi: 10.2134/agronj2006.0200.

THOMAS, H. Terminology and definitions in studies of grasslands plants. Grass and Forage Science, v.35, p. 13-23, 1980.

WILM, H.G. et al. Estimating forage yield by the double sampling method. Journal of American Society of Agronomy, v.36, p.194203, 1944. 